\title{
PEMBELAJARAN KONTEKSTUAL PADA PENDIDIKAN AGAMA BUDDHA
}

\author{
Oleh \\ Iin Suwarni \\ iin.suwarni@yahoo.co.id
}

\begin{abstract}
The purpose of education Buddhism is a fundamental issue of human life. Enterprises realize the goal of Buddhist education in schools one of which is through the development of strategies that focus on the creativity of students through direct practice of the material that has been studied. By learning Buddhist education which prioritizes direct practice, students can direct the construction of knowledge of Buddhism in the context of the life of the world real life. Here we describe the contextual learning, and learning implementation of contextual in Buddhism education. The method used in this paper is a qualitative research method, especially library research. For teachers to be able to implement contextual learning in Buddhism education. For students through the implementation of contextual learning in Buddhist education is expected to have a contextual knowledge of Buddhism.
\end{abstract}

Keywords: Contextual Learning, Pendidikan Agama Buddha

\section{Pendahuluan}

Sistem pendidikan nasional sebagaimana dinyatakan dalam pasal 1 Undang-undang No. 20 tahun 2003 adalah keseluruhan komponen pendidikan yang terkait secara terpadu untuk mencapai tujuan pendidikan nasional (Penyusun, 2003: 3). Tujuan pendidikan ini salah satunya dapat terwujud dengan memberikan keterandalan, membangun kemauan, dan membangun kreativitas peserta didik dalam proses pembelajaran.

Peran serta guru dalam dunia pendidikan formal adalah sebagai fasilitator yang menghantarkan peserta didik dalam memperoleh pengetahuan dan ketarampilan sesuai dengan kompetensinya masing-masing. Guru Pendidikan Agama Buddha memiliki peran penting dalam mewujudkan peserta didik untuk memiliki keyakinan terhadap Tuhan Yang Maha Esa, berkepribadian dan bertingkah laku baik serta memiliki kemampuan mengaktualisasikan ajaran Buddha dalam kehidupan sehari-hari. 
Tujuan Pendidikan Agama Buddha di sekolah adalah memberikan kemampuan peserta didik tentang agama Buddha untuk menerapkan kehidupan beragama, sehingga menjadi umat Buddha yang memiliki keyakinan terhadap Tuhan Yang Maha Esa, serta dapat mengikuti pendidikan yang berjenjang. Antara peran Guru Pendidikan Agama Buddha dan tujuan Pendidikan Agama Buddha memiliki keselarasan, sehingga apabila guru melakukan tugasnya dengan maksimal maka tujuan akan tercapai. Keberhasilan proses pembelajaran Pendidikan Agama Buddha di sekolah ditentukan oleh beberapa faktor yang meliputi: guru, kurikulum, program, sistem pembelajaran, sarana, fasilitas, alam, sosial budaya, kondisi fisiologis umum, kondisi panca indera, minat, kecerdasan, bakat motivasi dan kemampuan kognitif. Faktor ini saling berkaitan antara satu dengan yang lainya, kesenjangan antara faktor-faktor ini menjadi masalah bagi guru dalam proses pembelajaran (Tim Penyusun,2001: 4).

Sistem pembelajaran kontekstual merupakan strategi pembelajaran mencakup petunjuk spesifik untuk menciptakan lingkungan belajar yang efektif, cara merancang rencana pembelajaran, cara menyampaikan isi dan memudahkan kontruksi pengetahuan yang dibangun secara bertahap melalui pemahaman langsung serta aplikasi dalam kehidupan nyata siswa yang diapresiasikan pada perubahan tingkah laku.

Konsep pembelajaran kontekstual terdiri dari Kontruktivisme (Constructivism), Bertanya (Questioning), Menemukan (Inquiry), Masyarakat Belajar (Learning Community), Pemodelan (Modeling), Refleksi (Reflection), dan Penilaian Otentik (Authentic Assement) (Suyadi,2013: 32). Kontruktivisme (Constructivism) merupakan suatu kegiatan siswa membangun sedikit demi sedikit pengetahuan yang dimiliki siswa. Kegiatan ini bertujuan siswa belajar bukan hanya menghafal melainkan melalui pengalaman sehingga akan lebih bermakna. Kontruktivisme adalah proses membangun atau menyusun pengetahuan dalam struktur kognitif siswa berdasarkan pengalaman.

Kegiatan bertanya (Questioning) dalam proses pembelajaran, pengajuan pertanyaan dapat dilakukan guru dengan siswa, siswa dengan guru, siswa dengan siswa bahkan siswa dengan orang lain (nara sumber) sebagai upaya guru dalam membimbing siswa, menggali informasi dan menilai sejauh mana 130 |Jurna 1 V i j jacariya Vol.3 Nomor 1 Tah un 2016 
kemampuan yang telah diperoleh siswa. Dilanjutkan dengan kegiatan menemukan (Inquiry) yaitu suatu kegiatan siswa untuk berusaha menemukan sendiri pengetahuan bukan merupakan hasil mengingat fakta-fakta. Dalam hal ini guru hanya berfungsi sebagai fasilitator.

Konsep berikutnya adalah Masyarakat Belajar (Learning Community) merupakan kegiatan siswa memperoleh hasil belajar dari bekerja sama atau bertukar pendapat dengan orang lain. Bersama-sama dengan kelompoknya merumuskan suatu konsep. Pada konsep Pemodelan (Modeling), siswa memberi suatu contoh nyata yang ditunjukkan guru atau orang lain bisa asli atau tiruan dan bisa berbentuk demonstrasi, pemberian contoh tentang konsep-konsep.

Pada konsep Refleksi (Reflection) siswa berpikir kembali apa yang telah dilakukan dan apa yang akan diperoleh dalam proses kegiatan pembelajaran. Sedangkan pada konsep terakhir yaitu Penilaian Otentik (Authentic Assement) merupakan proses pengumpulan informasi oleh guru tentang perkembangan dan pencapaian pembelajaran yang dilakukan siswa melalui berbagai teknik yang mampu mengungkapkan, membuktikan atau menunjukkan secara tepat bahwa tujuan pembelajaran dan kemampuan (kompetensi) telah benar-benar dikuasai dan dicapai.

Pembelajaran kontekstual pada Pendidikan Agama Buddha merupakan strategi baru dalam pembelajaran Pendidikan Agama Buddha. Proses pembelajaran Pendidikan Agama Buddha dengan menggunakan pendekatan kontekstual menitikberatkan sentra pembelajaran berfokus pada kreativitas siswa melalui praktik langsung yang berhubungan dengan dunia nyata siswa serta membangkitkan inkuiri. Proses pencapaian inkuiri ini dilakukan dengan bimbingan guru melalui pelaksanaan model pembelajaran kontekstual yang dituangkan dengan pemberdayaan siswa aktif dan memperhatikan lingkungan kelas yang kondusif. Kedudukan pembelajaran kontekstual pada Pendidikan Agama Buddha adalah sebagai strategi yang digunakan untuk membantu guru agama Buddha mengkaitkan antara materi-materi Pendidikan Agama Buddha yang diajarkan sesuai dengan situasi dunia nyata. Implementasi dari 
pembelajaran ini adalah mendorong siswa mencapai inkuiri secara mandiri dan mengaplikasikan pengetahuan yang dimiliki tentang agama Buddha dalam kehidupan sehari-hari.

Peran pembelajaran kontekstual pada Pendidikan Agama Buddha adalah mengkontruksikan pemahaman siswa tentang ajaran agama Buddha secara bertahap melalui pemahaman konteks dengan dunia nyata. Hubungannya dengan pendidikan kontekstual, Buddha dalam menguraikan hakikat dukkha kepada lima orang pertapa menggunakan metode pemahaman yang berasal dari pengalaman nyata para siswa. Penyampaian ajaran ini dengan mengkaitkan antara pengalaman siswa tentang $d u k k h a$ dalam kehidupan nyata yaitu, ...."lahir, sakit, tua, mati, berkumpul dengan yang dibenci dan berpisah dengan yang dicinta adalah dukkha"...(S.V.420-421). Sehingga para siswa mampu mencapai penembusan kausalitas melaui konteks pemahaman berdasarkan pengalaman nyata yang dialami dalam kehidupan sehari-hari. Maka melalui pendekatan kontekstual siswa mampu menjangkau pemahaman analisis tingkat tinggi dalam memecahkan suatu permasalahan.

Keberadaan pembelajaran kontekstual pada Pendidikan Agama Buddha akan memberikan arti penting bagi peningkatan kualitas Pendidikan Agama Buddha di sekolah. Pembelajaran kontekstual Pendidikan Agama Buddha dikembangkan dengan tujuan agar pembelajaran Pendidikan Agama Buddha berjalan lebih produktif dan bermakna bagi siswa. Pelaksanaan pembelajaran kontekstual sebagai strategi dalam Pendidikan Agama Buddha adalah rancangan pembelajaran yang mencakup sumber masukan dari peserta didik agama Buddha, proses pendidikan yang terkait dengan pelaksanaan Pendidikan Agama Buddha dan hasil pendidikan dari proses pembelajaran agama Buddha.

Kegiatan pembelajaran Pendidikan Agama Buddha pada umumnya masih banyak menggunakan sistem tradisional (tekstual) yang berfokus pada guru sebagai sumber pengetahuan mutlak, belum terdapat perencanaan pembelajaran yang mengarah pada inkuiri, dan kurang mengembangkan kreativitas siswa. Pembelajaran tradisional hanya akan mencapai hasil akhir dalam bentuk pemahaman yang bersifat kognitif (teks) dan kurang terjadi perubahan tingkah laku secara konteks pada diri siswa dalam kehidupan nyata 
sesuai dengan ajaran agama Buddha. Sehubungan dengan permasalahan di atas, penulis tertarik untuk mencoba menyusun sebuah artikel kualitatif deskriptif kajian pustaka tentang: "Pembelajaran Kontekstual Pada Pendidikan Agama Buddha".

\section{Pembahasan}

Pembelajaran memerlukan pengetahuan profesional untuk menciptakan iklim belajar siswa secara optimal. Guru dalam pembelajaran berperan membantu siswa agar dapat memperoleh ilmu pengetahuan dengan mudah melalui strategi memanfaatkan lingkungan. Maka guru perlu mempersiapkan strategi pembelajaran yang tepat dan sesuai dengan karakteristik siswa sehingga dapat mencapai tujuan pembelajaran secara optimal meliputi aspek kognitif, afektif dan psikomotorik.

Pembelajaran kontekstual menurut kajian Agama Buddha mengacu pada ajaran Buddha tentang pemahaman hakikat tentang dukkha. Metode penyampaian hakikat dukkha dilakukan berdasarkan pemahaman siswa pada peristiwa-peristiwa nyata yang dialami dalam kehidupan sehari-hari. Peristiwaperistiwa nyata yang digambarkan oleh Buddha yaitu berkumpul dengan orang yang dibenci, berpisah dengan orang yang dicintai, keinginan yang tidak tercapai, dan segala fenomena nyata yang selalu berubah. Melalui analisa praktik langsung terhadap peristiwa nyata tersebut mendorong pemahaman para siswa untuk menemukan konsep secara nyata bahwa segala sesuatu adalah tidak kekal. Berdasarkan konsep anicca tersebut para siswa dapat mengkontruksikan hubungkan pengetahuan nyata menuju kepada yang abstrak yaitu pencapaian penembusan bahwa segala sesuatu yang tekondisi adalah $d u k k h a(S . V .420-421)$.

Pembelajaran serupa disampaikan Buddha melalui penggunaan perumpamaan binatang dan pepohonan. Binatang dan pepohonan digunakan sebagai alat oleh Buddha dalam pembelajaran dimaksudkan agar para siswa dapat lebih mudah dalam mencerna pengetahuan yang disampaikan, sehingga dapat direalisasikan dalam kehidupan sehari-hari. Hutan dan pepohonan pada 
saat itu merupakan kondisi yang sesuai dengan karakteristik siswa sehingga melalui perumpamaan tersebut siswa dapat mengkontruksi pengetahuan sesuai dengan situasi dunia nyata.

Buddha memberikan petunjuk belajar melalui starategi pengajaran yang luar biasa, disesuaikan dengan karakteristik siswa, sehingga strategi ini mampu membuat para siswa gembira dan dapat memperoleh manfaat yang besar sesuai dengan praktik (A.I.267).

\section{Asas Utama Pembelajaran Kontekstual}

Asas fundamental pembelajaran kontekstual adalah bersandar pada filosofi bahwa belajar akan lebih bermakna apabila siswa mengalami bukan mengetahui. Belajar menjadi lebih bermakna apabila siswa mengalami menurut kajian peneliti mengacu pada pengubahan struktur pembelajaran yang berfokus pada praktik langsung siswa. Pentingnya pengalaman belajar secara langsung pada siswa dalam proses pembelajaran di kelas, akan memberikan bentuk pemahaman baru yang luas tentang suatu ilmu pengetahuan. Aplikasi guru pada sistem ini dengan membawa siswa ke dalam pembelajaran yang berfokus pada praktik-praktik langsung, sehingga siswa akan termotivasi untuk memaknai dan mengorganisasi sendiri pembelajaran yang dialami serta dapat mengkontruksi pemahaman baru yang diperoleh secara bertahap berdasarkan pengalaman nyata yang dialami.

Proses pembelajaran yang berfokus pada kegiatan praktik siswa adalah berupa persiapan rancangan pembelajaran yang mendasarkan pada praktikpraktik nyata dalam setiap sub pokok bahasan yang akan disampaikan oleh guru. Rancangan pembelajaran dalam bentuk praktik nyata dalam setiap bahasan ini diarahkan untuk lebih melibatkan siswa aktif dalam belajar, baik secara mental, intelektual, fisik, maupun sosial dan pembelajaran perlu disesuaikan dengan kekhasan konsep serta perkembangan tingkat berpikir siswa. Pembelajaran melalui praktik langsung oleh siswa menurut kajian ajaran Buddha mengacu pada pelaksanaan praktik menjalani kehidupan suci sesuai dengan Dhamma. Praktik tersebut dilakukan dengan cara mengendalikan nafsu kesenangan indera serta menjaga pikiran, ucapan dan perbuatan. Melalui praktik 
akan mengkondisikan para siswa untuk menemukan kedalaman makna sebenarnya tujuan dari menjalani kehidupan suci (M.I.13).

Kajian ajaran Buddha terhadap asas ini ditunjukan dalam metode pembelajaran Buddha yang mengutamakan pemberdayaan siswa untuk dapat mengetahui pemahaman tentang kewaspadaan. Perenungan secara langsung terhadap empat unsur tubuh oleh para siswa dapat menghantarkan pada pengetahuan mendalam secara mandiri dan dapat mengarahkan para siswa pada tingkat pengetahuan kewaspadaan yang bertahap. Asas pembelajaran kontekstual dapat diimplementasikan dalam pembelajaran agama Buddha misalnya pada sekolah dasar tentang sub pokok bahasan arti dukkha. Pembelajaran Pendidikan Agama Buddha di sekolah dasar pada sub pokok bahasan arti $d u k k h a$ berdasarkan azas pembelajaran kontekstual dapat dilakukan dengan membawa siswa untuk terlibat secara langsung dalam pembelajaran. Langkah pembelajaran tersebut adalah menjadikan siswa sebagai media praktik agar dapat mengenal konsep dukkha secara sederhana sesuai dengan pengalaman nyata.

Siswa sebagai media praktik dapat dilakukan dengan memberikan beberapa pertanyaan yang mudah dipahami oleh siswa tentang peristiwaperistiwa yang berhubungan dengan kondisi $d u k k h a$, misalnya menanyakan kepada siswa bagaimana perasaanya saat diberi hadiah oleh orang tuanya dan bagaimana perasaanya saat ditinggal pergi keluar kota oleh orang tuanya. Perbandingan antara perasaan senang dan perasaan sedih tersebut dapat mempermudah guru dalam menjelaskan pengertian dukkha kepada siswa. Pertanyaan yang diberikan kepada siswa tentang pengalaman nyata yang berhubungan dengan peristiwa dukkha dapat memotivasi siswa dalam menumbuhkan pemahaman tentang konsep dukkha.

Pemahaman siswa melalui praktik dapat memberikan makna lebih mendalam tentang hakikat pengertian dukkha yang sebenarnya, dibandingkan dengan pembelajaran yang dilakukan secara tekstual. Buddha mengajarkan bahwa praktik melalui perenungan peristiwa yang saling berkaitan dapat 135 | J u r a 1 V i j j a c a ri y a V o 1.3 Nom or 1 T a h u n 2016 
menumbuhkan pengetahuan siswa secara bertahap dan akan membimbing pada pengetahuan sempurna (D.II.292).

\section{Prinsip Sistem Pembelajaran Kontekstual}

Pembelajaran kontekstual memiliki prinsip atau komponen yang mempengaruhi seluruh aspek pendekatan kontekstual meliputi pengembangan belajar mandiri, menemukan sendiri, mengkontruksi pengetahuan inkuiri baru, mengembangkan sikap bertanya, masyarakat belajar, menghadirkan model, melakukan refleksi, melakukan penilaian. Prinsip pembelajaran kontekstual dalam kajian ajaran Buddha mengacu rancangan pembelajaran Buddha yang menekankan pada pemberdayaan siswa dalam bentuk praktik yang sesuai dengan karakteristik siswa. Aktualisasi praktik menurut ajaran Buddha dilakukan melalui tindakan (sila), konsentrasi (samadhi) sempurna, dan kebijaksanaan (panna) sebagai hasil (Dhp.A.144). Sehingga melalui praktik tersebut para siswa dapat memperoleh pengetahuan secara mendalam tentang ajaran Buddha dalam bentuk pemahaman bertingkat yang mengarahkan pada pengetahuan sempurna.

\section{Model Pendekatan Kontekstual}

Model pembelajaran kontekstual merupakan aplikasi asas dan prinsip pembelajaran kontekstual yang dituangkan dalam kegitan belajar mengajar. Model pembelajaran kontekstual meliputi tujuh komponen dasar pembelajaran efektif dan kondusif yang dapat menghantarkan siswa pada tingkat pemahaman pengetahuan sesuai dengan dunia nyata. Tujuh komponen dasar pembelajaran efektif merupakan keahlian guru dalam mengaplikasikan rancangan pembelajaran berdasarkan keaktifan siswa yang meliputi semua bagian untuk mengkonstruksi (contructivism), bertanya (questioning), menemukan (inquiry), membentuk masyarakat belajar (learning community), pemodelan (modeling), refleksi (reflection) dan penilaian yang sebenarnya (authentic assesment).

Kontruksi (contructivism) merupakan landasan dasar pendekatan kontekstual yang digunakan untuk mengkontruksi pemahaman siswa berdasarkan pengalaman. Inti dari pelaksanaan model kontruksi adalah 
mengarahkan siswa agar dapat memahami makna pembelajaran secara mendalam bukan mengarahkan siswa target penguasaan materi pembelajaran. Melalui pemahaman secara mendalam berdasarkan pengalaman tentang ilmu pengetahuan siswa dapat mengkontruksi pengetahuan secara bertahap dan mengaplikasikan sesuai dengan kehidupan nyata.

Kontruksi dikaji berdasarkan ajaran agama Buddha merupakan bentuk praktik langsung yang dapat mengarahkan pada kemajuan batin secara bertahap. Kemajuan batin secara bertahap dapat dilakukan berdasarkan latihan secara berjenjang dari praktik nyata menuju pada praktik yang abstrak (M.III.124). Latihan berjenjang dari praktik yang nyata menuju pada praktik yang abstrak dimaksudkan praktik menjalani kehidupan suci dapat dilakukan melalui bentuk dasar sampai pada aplikasi yang lebih mendalam. Latihan fundamental dalam kehidupan spiritual dapat dilakukan mulai dari pelaksanaan peraturan menjalani kehidupan spiritual dengan pengendalian diri terhadap napsu indera, pikiran, ucapan, dan perbuatan. Pelaksanaan latihan fundamental secara sempurna dalam menjalani kehidupan spiritual dapat mendorong para siswa untuk mengembangkan pengetahuan yang lebih tinggi. Buddha mengajarkan praktik bertahap adalah jalan untuk mencapai pengetahuan sempurna (M.III.214). Pencapaian tingkat kesucian bhikkhu Culapanthaka merupakan salah satu contoh metode pembelajaran Buddha yang menggunakan model inkuiri. (DhpA.25).

Berdasarkan uraian model inkuiri tersebut dapat disimpulkan bahwa inkuiri merupakan model pembelajaran yang menekankan siswa untuk memecahkan masalah, merencanakan eksperimen, melakukan eksperimen, mengumpulkan, menganalisis data, menarik kesimpulan. Pelaksanaan model inkuiri ini menuntut siswa terlibat secara mental maupun fisik untuk memecahkan suatu permasalahan yang diberikan guru. Buddha mengajarkan bahwa praktik langsung terhadap Dhamma secara tekun dapat membawa siswa pada pemahaman realitas dan ketidakkekalan kehidupan (nibbana) (S.V.789). 
Diskripsi hasil (output) dalam pembelajaran kontekstual pada Pendidikan Agama Buddha adalah menggambarkan perubahan pengetahuan siswa dalam bentuk tindakan yang sesuai dengan pokok bahasan pelajaran agama Buddha. Perubahan pengetahuan siswa tersebut dituntut untuk diwujudkan dalam perbuatan secara konteks bukan pada penguasaan secara tekstual. Melalui bentuk tindakan secara konteks mendorong siswa untuk dapat memecahkan persoalan kehidupan nyata berdasarkan ajaran agama Buddha.

\section{Penutup}

Pembelajaran kontekstual pada Pendidikan Agama Buddha secara teoritis yaitu implementasi pembelajaran kontekstual pada Pendidikan Agama Buddha melalui aplikasi asas, prinsip dan model pembelajaran kontekstual yang menekankan pemberdayaan siswa aktif agar dapat mencapai pemahaman inkuiri secara konteks tentang pokok bahasan pelajaran agama Buddha. Keberhasilan guru dalam penggunaan komponen dasar pembelajaran kontekstual di sekolah dapat menjadikan pembelajaran agama Buddha lebih bernilai dan bermakna bagi siswa serta sebagai bentuk peran serta dalam mewujudkan tujuan pendidikan nasional. Guru agama Buddha disarankan agar menggunakan strategi pembelajaran yang lebih menekankan pada kreativitas siswa melalui praktik. Sehingga strategi pembelajaran yang digunakan bukan menjadikan siswa sebagai robot, tetapi lebih menekankan makna dari pembelajaran yang dipelajari. Strategi pembelajaran tersebut salah satunya adalah strategi pembelajaran kontekstual.

\section{Daftar Pustaka}

Bransford JD. Landasan Sistem Pembelajaran Kontekstual. (online), http: /www.millville.cache.kl2.ut.us./Millville/Teachers/Carles/ phllosophy/contruc.htm, (diakses November 2016).

Deni Swarja. 2008. KBK Tantangan Profesionalitas Guru. (online). http: /www.depdiknas.go.id.kbk.html, (diakses November 2016).

Dhammapada Atthakatha. Terjemahan oleh Tim Penerjemah Vidyasena, 2003, Yogyakarta: Vidyasena Vihara Vidyaloka.

Dhammapada. Terjemahan oleh Surya Widya, 2002. Jakarta: Yayasan Abdi Dhamma Indonesia. 
Dikdasmen. 2011. Bahan Dasar Wawasan Kependidikan Guru Agama Buddha SLTP (I). Jakarta: Depdiknas Dirjen Pendidikan Dasar dan Menengah.

Handayani. 2004. Penelitian Pembelajaran Kontrukstivim. (online), http: /www.depdiknas.go.id, (diakses November 2016).

Indaratano. 2003. Siswa-siswa Utama Sang Buddha. Jakarta: Wanita Theravada Indonesia.

Nanamoli. Tanpa Tahun. Majima Nikaya (I). Terjemahan oleh Lanny Anggawati, Wena Cintiawati. 2002. Klaten: Vihara Bodhivamsa.

Nurhadi. 2002. Pendekatan Kontekstual (Contextual Teaching and Learning). Jakarta: Departemen Pendidikan Nasional Direktorat Jendral Pendidikan Dasar dan Menengah Direktorat Pendidikan Lanjutan Pertama.

Nyanaponika.Petikan Anguttara Nikaya (I). Terjemahan oleh Lanny anggawati. 2001. Klaten: Vihara Bodhivamsa.

Petikan Anguttara Nikaya (III). Terjemahan oleh Lanny anggawati. 2002. Klaten: Vihara Bodhivamsa.

Suyadi.Strategi Pendidikan Karakter.2013.Bandung

Tim Penyusun. Tanpa tahun. Format Pendidikan Buddhis Abad 21. Jakarta: Buddha Gautama Society.

Wijaya Mukti, Krisnanda. 2003. Wacana Buddha Dhamma. Jakarta: Yayasan Pembangunan. 